\title{
Effect of Heat Treatment Processes on the Mechanical Properties of Medium Carbon Steel
}

\author{
T. Senthilkumar ${ }^{1, *}$ and T. K. Ajiboye ${ }^{2}$ \\ ${ }^{1}$ Department of Mechanical Engineering, Anna University of Technology, \\ Tiruchirappalli, 620 024, India \\ ${ }^{2}$ Department of Mechanical Engineering, University of Ilorin, Ilorin, Nigeria \\ *Corresponding Author: engrtkajiboye@yahoo.com
}

\begin{abstract}
The importance of various form of heat treatment operations on medium carbon steel in order to forester the problem that may arise in making a wrong choice of these steel materials or faulty heat treatment operations which may give rise to serious disruption in terms of human safety, higher cost and untimely failure of the machine components is of great concern. The mechanical properties such as ductility, toughness, strength, hardness and tensile strength can easily be modified by heat treating the medium carbon steel to suit a particular design purpose. Tensile specimens were produced from medium carbon steel and were subjected to various forms of heat treatment processes like annealing, normalizing, hardening and tempering. The stiffness, ductility, ultimate tensile strength, yield strength and hardness of the heat treated samples were observed from their stress-strain curve. The value of the yield strength $\left(\sigma_{y}\right)$ was observed to be higher for the tempered specimen possibly as a result of the grain re-arrangement, followed by the hardened, normalized and annealed specimens. The value of the ultimate tensile strength $\left(\sigma_{u}\right)$ were also observed to be in the order; hardened $>$ tempered $>$ normalized $>$ annealed.
\end{abstract}

Key Words: Medium carbon steel, Austenite, Martensite, Strain hardening parameter, Ductility

\section{INTRODUCTION}

Heat treatment operation is a means of controlled heating and cooling of materials in order to effect changes in their mechanical properties. Heat treatment is also used to increase the strength 
of materials by altering some certain manufacturability objectives especially after the materials might have undergo major stresses like forging and welding [1]. It was however known that mechanical properties of steel were strongly connected to their microstructure obtained after heat treatments which are performed to achieve good hardened and tensile strength with sufficient ductility [1]. The material modification process, modify the behavior of the steels in a beneficial manner to maximize service life i.e stress relieving or strength properties e.g cryogenic treatment or some other desirable properties [2]. The Heat treatment generally is classified into (i) Thermal treatment which consists of softening process: Annealing and Normalizing, Hardening process: Hardening and Tempering; (ii) Thermochemical Process which consist of Carburizing, Nitriding, Boronising; (iii) Thermomechanical Processes which consist of mechanical working operation during heat treatment cycle. Though heat treatment is not a new area, it has not been put into effective use in the fact that most of the researchers look at the process in general. It has not been localized for an improvement/modification on getting the required results from these steel materials that are abound in our daily life, especially where most of the steel products are from recycled scrap materials. Hence there is a need to carry out these tests and to be sure of the material compositions before they are put to final use.

Present work is concerned with the effect of heat treatment on the mechanical properties of medium carbon steel with the objective of making sure that the steel is better suited structurally and physically for individual engaging in the design, fabrication and maintenance of steel products.

\section{METHODS OF ANALYSES}

To evaluate the effect of heat treatment on the medium carbon steel, the investigation was carried out thus;

(i) Preparation of the tensile specimens from $0.30 \%$ carbon steel

(ii) Heat treating the medium carbon steel

(iii) Tensile test of the medium carbon steel to analyze its behavior after the treatment

\subsection{Preparation of the Tensile Specimens}

The material used for this study is a medium carbon steel with carbon content of $0.30 \%$ carbon as determined by X-ray diffraction technique. The specimens were then prepared for a tensile test using a standard format of ASTM [3, 4] as shown in Figure 1(a). 


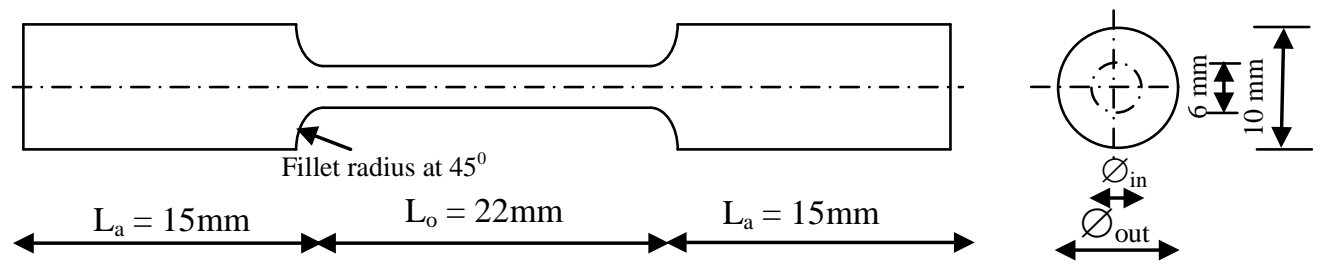

Figure 1(a): Test specimen from medium carbon steel. $\varnothing_{\text {out }}=$ Diameter of gripping heads; $\varnothing_{\text {in }}=$ Diameter of the gauge length; $L_{a}=$ Minimum gripping length; $L_{o}=$ gauge length.

\subsection{Heat treating the Medium Carbon Steel}

Standard heat treatment procedures were adopted $[3,4]$ to heat treat the medium carbon steel. Five different samples were prepared for each of the operation and the average values were calculated upon which the analyses were based.

\subsection{Tensile Test of the Medium Carbon Steel}

After the specimens had been heat treated as appropriate, the tensile test were carried out on them to determine the mechanical properties of the steel and compare it with the non heat treated specimen which was also subjected to the same tensile test.

\section{EXPERIMENTS}

After careful preparation of the tensile specimen samples from the medium carbon steel, it was taken to the furnace for the heat treatment operations. To commence the operation, the furnace was initially calibrated to determine the furnace operating temperature based on the pre-set furnace temperature. To determine this, the furnace was set to an initial temperature of $200^{\circ} \mathrm{C}$ and the furnace was switched on. This temperature was maintained with the aid of thermostat that was used to control the furnace temperature. On attaining this temperature, a thermocouple was now introduced into the furnace chamber to measure and compare the temperature of the chamber which was adjusted until it give same output temperatures. The various forms of the heated processes were stated below.

\subsection{Heat Treatment Process}

\subsubsection{Hardening process}

The specimens to be hardened were placed inside the furnace and heated to a temperature of 
$850^{\circ} \mathrm{C}$. At this temperature, there is transformation of the steel to austenite. The samples were retained at this temperature for a period of two hours (because of its mass) during which the transformation must have been completed, after which they were later removed from the furnace and dropped inside different containers of water for rapid cooling to room temperature. The hardening operation was carried out on five medium carbon steel samples having the same dimensions

\subsubsection{Tempering process}

In the hardened carbon steel specimens, the as-quenched martensite is not only very hard but also brittle. The brittleness is caused by a predominance of martensite. This brittleness is therefore removed by tempering [5]. Tempering results in a desired combination of hardness, ductility, toughness, strength and structural stability. The process of tempering involves heating the hardened steel specimen to $350^{\circ} \mathrm{C}$. At this temperature, the prevalent martensite is an unstable structure and the carbon atoms diffuse from martensite to form a carbide precipitate and the concurrent formation of ferrite and cementite. This process allows microstructure modifications to reduce the hardness to the desire level while increasing the ductility.

\subsubsection{Annealing process}

A full annealing was carried out on the specimen by heating the metal slowly at $870^{\circ} \mathrm{C}$. It is held at this temperature for sufficient time (about 1 hour) for all the material to transform into austenite. It is then cooled slowly inside the furnace to room temperature. The grain structure has coarse pearlite with ferrite or cementite.

\subsubsection{Normalizing process}

Each samples of the medium carbon steel to be normalized were placed in the furnace and heated to temperature of $850^{\circ} \mathrm{C}$. The samples were retained at this temperature for the period of two hours for full transformation to austenite. They were later removed from the furnace and left in air for cooling. Meanwhile another set of the sample specimens which were not heat treated were taken directly for the tensile test to serve as control samples.

\subsection{Material Testing}

After the successful heat treatment operation, the various heat treated samples were taken for the tensile test. The test was performed on Standard Universal Testing Machine. Tensile tests were conducted at various strain rates of 200, 500, 1000, 1500 and $1650 \mathrm{~mm} / \mathrm{min}$ for all the specimens. 
Each of the specimens was inserted one after the other into the machine jaws and having fastened the specimen properly at both ends, tensile test upto the fracture limit was carried out. The arrangement is shown in Figure 1(b).

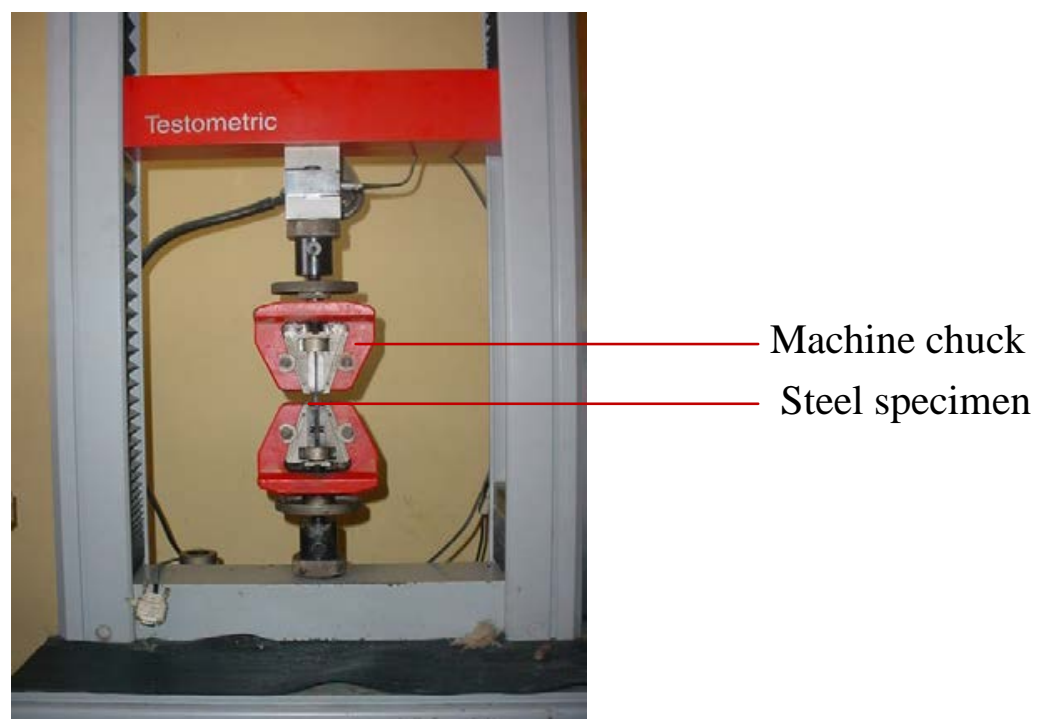

Figure 1(b): The arrangement of the specimen on the machine chuck

The machine recorded the stress, strain, elongation, yield strength and Ultimate tensile strength for all the specimens which were used for further analysis.

The stress/strain values obtained from the tensile test gave the engineering stress/strain values which were based on the original cross sectional area of the test specimens. These values were later converted to true stress/strain values using the relationship given below [6, 7]

$$
\begin{aligned}
& \varepsilon_{\text {true }}=\ln \left(1+\varepsilon_{\text {engineering }}\right) \\
& \sigma_{\text {true }}=\sigma_{\text {engineering }}\left(1+\varepsilon_{\text {engineering }}\right)
\end{aligned}
$$

From these values, a non linear regression analysis was used to obtain the material constants.

\section{RESULTS AND DISCUSSION}

The heat treated specimens were now subjected to tensile test, using standard universal testing machine U.T.M (Tensometer), which is calibrated in unit of Newton. The resulting engineering stress - strain curves obtained from the test are shown in Figures 2 to 5 for annealed, normalized, tempered and hardened specimens respectively.

The data generated from these graphs for each of the specimens were converted to true stress strain data using equations 1 and 2 and were analyzed for various heat treated specimens, using 
non regression analysis to obtain the material related properties for each of the specimen. The material related properties obtained were shown in Table 1.

Table 1: The materials property for different heat treated specimens based on true-stress strain data

\begin{tabular}{cccccc}
\hline Operation & $\sigma_{\boldsymbol{y}}(\mathbf{M P a})$ & $\boldsymbol{\sigma}_{\boldsymbol{u}}(\boldsymbol{M P a})$ & $\boldsymbol{C}$ & $\boldsymbol{n}$ & $\boldsymbol{m}$ \\
\hline Annealed & 270 & 410 & 0.0562 & 0.0267 & 0.98495 \\
Normalized & 330 & 460 & 0.0830 & 0.0308 & 1.1144 \\
Tempered & 440 & 610 & 0.0274 & 0.2500 & 1.12615 \\
Hardened & 650 & 700 & 0.0143 & 0.0400 & 0.8442 \\
\hline
\end{tabular}

From Table 1, $\sigma_{\mathrm{y}}$ is the yield strength $\left(\mathrm{kN} / \mathrm{mm}^{2}\right)$ while $\sigma_{\mathrm{u}}$ is the ultimate tensile strength of the material $\left(\mathrm{kN} / \mathrm{mm}^{2}\right)$ at room temperature and a strain rate of $1 / \mathrm{s}$. C is the strain - rate sensitivity constant, $\mathrm{n}$ is the strain hardening parameter and $\mathrm{m}$ is the thermal softening parameter for each specimen.

The value of yield strength $\left(\sigma_{\mathrm{y}}\right)$ was observed to be higher for the tempered steel specimen, possibly as a result of the grain re-arrangement due to the subsequent tempering process. The yield strength value for the hardened specimen was also observed to be greater than that of normalized and annealed specimens, while the normalized specimen also has a greater value than that of annealed specimen, which has the least value. Because of the dual phase strengthening mechanics, the plain carbon steel has a good balance of strength and ductility. The hardness of the steel increases with cooling rate and also with increasing pearlite percentage which increased as the percentage mertensite increases. The reason being that martensite is one of the strengthening phases in steel. The increase in the hardness was due to the delay in the formation of peatrlite and martensite at a higher cooling rate.

The value of ultimate tensile strength $\left(\sigma_{\mathrm{u}}\right)$ were observed to be in the order; hardened $>$ tempered $>$ normalized $>$ annealed, possibly as a result of the refinement of the primary phase after the subsequent cooling processes. The higher the toughness of a material, the lower the slope of the stress-strain curve in the plastic region, hence the lower the strain hardening parameter. As the strain hardening parameter increases, the stress of the material also increases. This can be justified from the Ludwik power law [8, 9] given as;

$\sigma=C \varepsilon^{n}$

where $\mathrm{C}$ and $\mathrm{n}$ are as defined above.

Beyond the yield point, the stress continuously increases with further plastic strain, while the slope of the stress-strain curves, representing the strain hardening steadily decreases with increasing stress $[10,11]$. 
It was also observed from the graphs that for all the heat treated specimens, except for the hardened specimen, there were tremendous increase in the toughness of the material which indicates that hardened material, though have a very high ultimate tensile stress $\left(\sigma_{u}\right)$, but at the expense of its toughness, hence where toughness is a major concern, the material should be oil tempered for a satisfactory results.

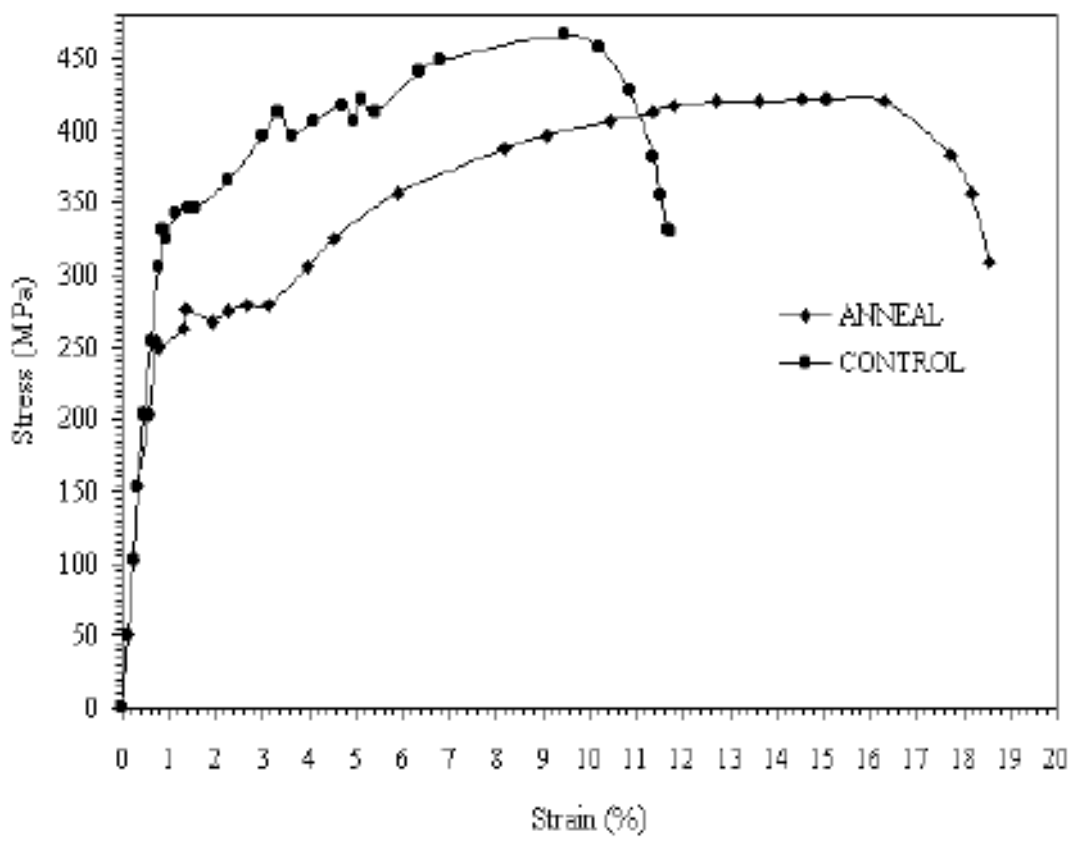

Figure 2: Stress versus strain curve for annealed and control specimens

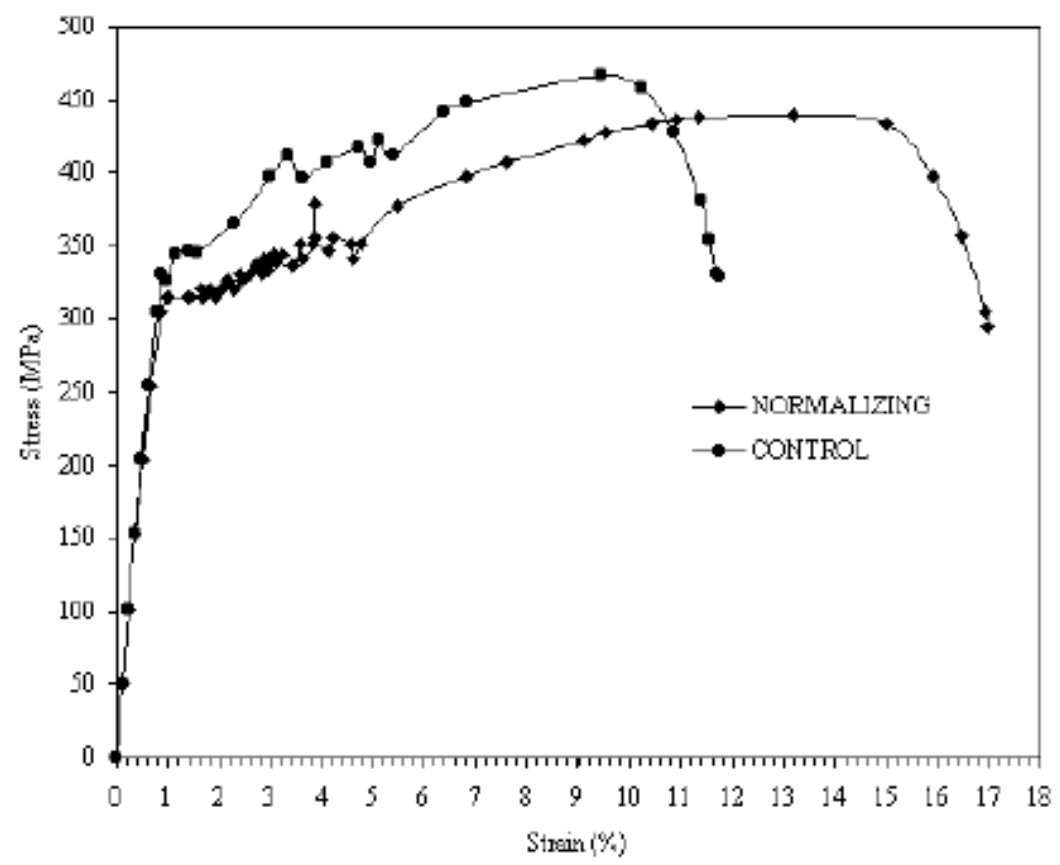

Figure 3: Stress versus strain curve for normalized and control specimens 
The strain produced for each of the specimen was in the order of annealed $>$ normalized $>$ tempered $>$ hardened as observed from Figures 2 - 5 which gave a clear indication of the final state of the materials as a result of the treatment received.

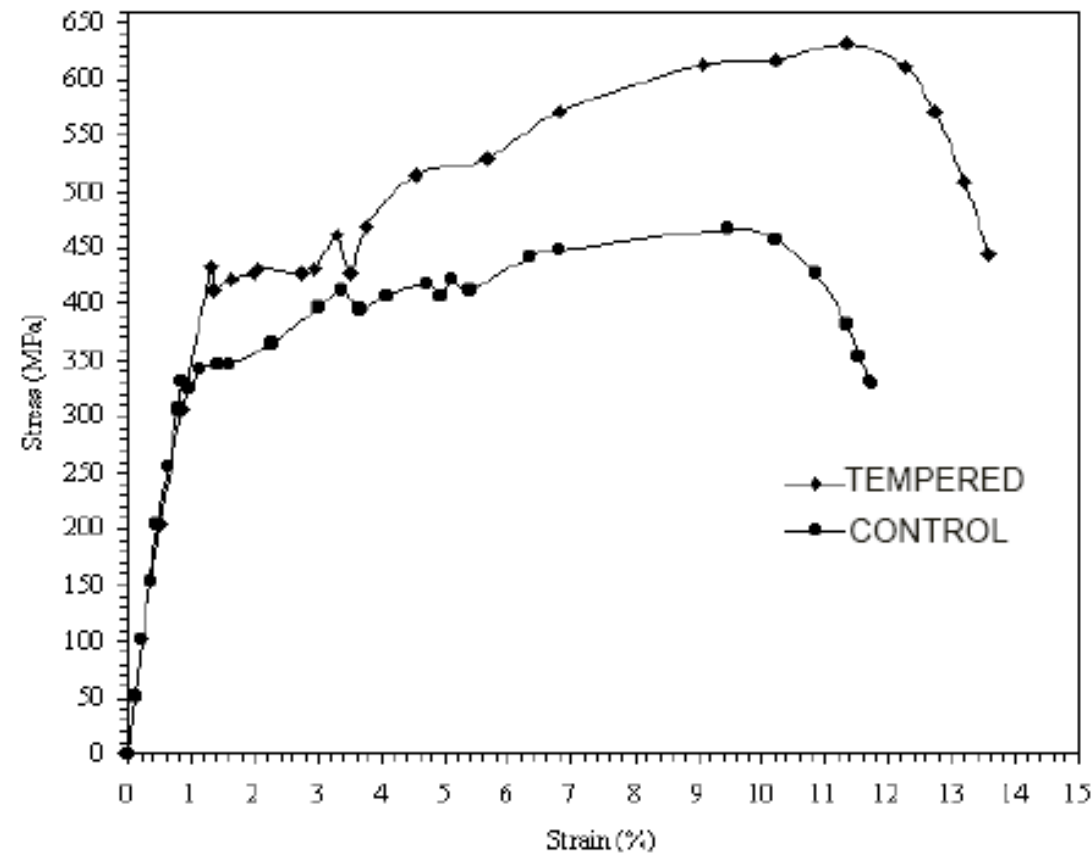

Figure 4: Stress versus strain curve for tempered and control specimens

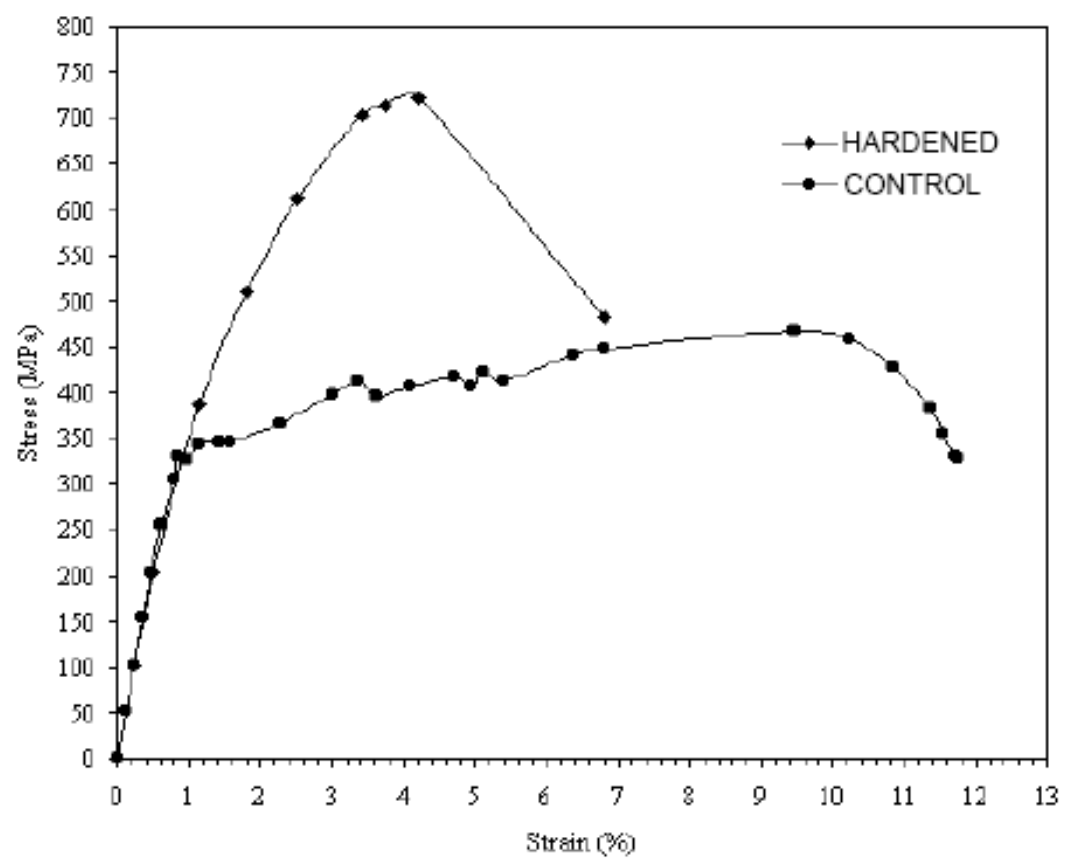

Figure 5: Stress versus strain curve for hardened (water quench) and control specimens 
Empirical relationships were also developed to determined various value of stresses at any given strain and strain rate for each of the specimen. The empirical relationships were given in equation 3 to 7 for normalized, tempered, annealed, hardened and as received specimen respectively.

$$
\begin{aligned}
& \sigma=76.32134 \varepsilon+0.244707 \dot{\varepsilon} \\
& \sigma=72.3241 \varepsilon+0.236757 \dot{\varepsilon} \\
& \sigma=166.25 \varepsilon-0.126 \dot{\varepsilon} \\
& \sigma=148.198 \varepsilon-0.13968 \dot{\varepsilon} \\
& \sigma=126 \varepsilon+0.236704 \dot{\varepsilon} \\
& \text { where } \\
& \sigma=\text { stress, } \\
& \varepsilon=\text { strain, and } \\
& \dot{\varepsilon}=\text { strain rate. }
\end{aligned}
$$

\section{CONCLUSION}

From the results obtained, it can be inferred that mechanical properties depends largely upon the various form of heat treatment operations and cooling rate. Hence depending upon the properties and the applications that may be required for any design purpose, a suitable form of heat treatment should be adopted. For high ductile and minimum toughness, annealing the medium carbon steel will give satisfactory results. Thus it is important to clearly specify the condition of the carbon steel as purchased so that tests can be conducted to ensure the material compositions before they are put to final use.

\section{REFERENCES}

[1] Adnan, Calik. Effect of Cooling rate on Hardness and Microstructure of AISI 1020, AISI 1040 and AISI 1060 Steels. Int J of Physics Sciences, vol. 4(9), pp. 514 - 518, 2009.

[2] S.Z. Qamar. Effect of Heat Treatment on Mechanical properties of H11 tool steel. J Achiv Mat and Manufact Eng, vol. 35(2), pp. 115 - 120, 2009.

[3] G.E. Totten (ed). Steel Heat Treatment Handbook. vol. 1. Metallurgy and Technologies, vol. 2, Equipment and Process Design, $2^{\text {nd }}$ edition. CRC Press, Boca Raton, 2007.

[4] ASTM International, ASTM Handbook, vol. 4, Heat Treating, American Society for Metals park, Ohio, 1991.

[5] Heat Treatment of Steel: Application and Heat Treatment of Society of Automobile Engineer, Carbon and alloy Steels, Machinery’s Hand Book, 1924.

[6] D.J. Daris and L.A. Oelmann, The structures, properties and Heat Treatment of metals. The Pitman Press, Great Britain, 1983. 
[7] Vijay Sharan Sony Ericsson, Stress-strain Modification - An Experimental and Analytical Investigation of the Large Strain Compressive and Tensile Response of Glassy Polymers, Polymer Eng and Science, vol. 30(20), pp. 1288-98, 1990.

[8] R.K. Jain and S.C. Gupta, Production Technology, A text book for Engineering students, Hanna Publishers, pp. 500 - 508, 1981.

[9] W.T. Lankford, N.L. Samwap, R.F. Craven and H.E. McGanno, The Making of Steel, $11^{\text {th }}$ edition, USS (United States Steel), 1985.

[10] P.C. Sharma, A Textbook of Production Engineering, S. Chand and Co. Ltd., New Delhi, India, 2003. 